\title{
Persistent Ductus Arteriosus in Critically Ill Preterm Infants
}

\author{
Maria Livia Ognean ${ }^{1 *}$, Oana Boantă${ }^{1}$, Simona Kovacs² ${ }^{2}$ Corina Zgârcea ${ }^{1}$, Raluca Dumitra ${ }^{1}$, \\ Ecaterina Olariu1 ${ }^{1}$, Doina Andreicuţ² \\ 1 Neonatology I, Clinical County Emergency Hospital Sibiu, Romania \\ 2 Neonatology II-Premature Infants, Clinical County Emergency Hospital Sibiu, Romania
}

\begin{abstract}
Introduction: Persistent ductus arteriosus (PDA) is found with increased incidence in preterm infants, significantly affecting neonatal morbidity and mortality rates.

Aim: To evaluate the association between the presence of PDA and the severity of clinical condition at birth in critically ill preterm infants, with gestational ages $(G A) \leq 32$ weeks and severe respiratory distress.

Methods: All preterm infants with GA $\leq 32$ weeks admitted to the neonatal intensive care unit (NICU) of the Clinical County Emergency Hospital, Sibiu between 1 January 2010 and 31 December 2015 were included in the study. These were categorized as Group 1 [Preterm infants with PDA; $n=154$ ] and Group 2 [Preterm infants without PDA; $n=186$ ]. Epidemiological and clinical data were collected in the National Registry for Respiratory Distress Syndrome for all children, and data related to prenatal period, clinical characteristics at birth i.e GA, weight, gender, Apgar scores, and clinical features such as resuscitation at birth, surfactant administration, need and duration of respiratory support, neonatal sepsis, complications associated with prematurity, and death, were analyzed.
\end{abstract}

Results: Group 1 infants had significantly lower GA and birth weights, were more often out born ( $p=0.049$, HR 1.69), and had significantly lower Apgar scores at 1 and 10 minutes $(p=0.022, p=0.000)$. They presented a significantly higher need for surfactant administration $(42.9 \%$ vs $24.7 \%, p<0.0001)$ and respiratory support $(96.8 \%$ vs $90.3 \%$, HR 3.19 , $\mathrm{p}=0.019$ for need of CPAP and $22.1 \%$ vs $10.8 \%, \mathrm{HR} 2.35, \mathrm{p}=0.004$ for mechanical ventilation). Duration of respiratory support was also significantly higher in the Group $1(7.6 \% \pm 7.5$ vs. $5.1 \pm 3.8$ days, $p<0.0001$ for CPAP and $20.1 \pm 22.5$ vs. $12.0 \pm 15.7$ days, $p<0.0001$ for mechanical ventilation).

Conclusion: In very preterm infants, PDA may be associated with a critical clinical condition leading to serious complications. The presence of PDA after the seventh day of life was associated with an increased need for respiratory support, both CPAP and mechanical ventilation, increased severity of the respiratory distress syndrome, requiring a longer duration of respiratory support, and increased the hospitalization length. In very preterm infants, PDA presence was also associated with a higher rate of severe complications and death, indicating the need for a careful and proper management of these critical cases in neonatal intensive care units.

Keywords: persistent ductus arteriosus, prematurity, respiratory distress syndrome, bronchopulmonary dysplasia, intraventricular hemorrhage

Received: 10 August 2016 / Accepted: 15 September 2016

\section{INTRODUCTION}

Ductus arteriosus (DA), described for the first time by Galen in the first century is an important vascular structure of the fetal circulation, connecting the proximal ascendant aorta to the pulmonary artery root, close to the left pulmonary branch artery $[1,2]$. After birth, as part of the transition to extra uterine life, the ductus closes due to increased arterial oxygen pres- sure, decreased pressure of the pulmonary blood flow, decreased concentration of prostaglandin E2, and decreased the number of the prostaglandin E2 receptors $[3,4]$. At term, spontaneous functional closure of DA occurs in $50 \%$ of the infants at 24 hours, in $90 \%$ of the cases at 48 hours, and in $100 \%$ of the cases at 72 hours of life $[5,6]$. Anatomical closure of the ductus occurs in 2-3 weeks [2]. Closure of DA often fails in preterm infants, mostly due to developmental immaturity $[2,6]$.

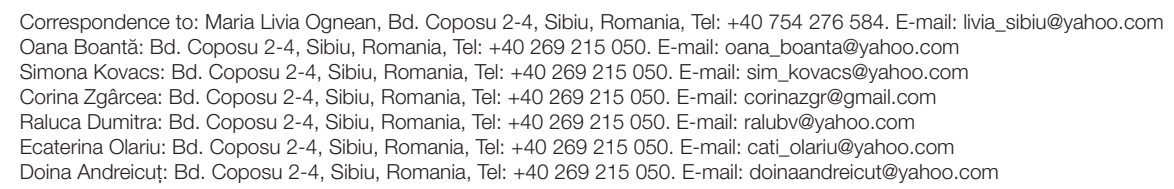


The term "patent ductus arteriosus" is an umbrella term covering all physiological and pathological situations related to an open DA [7]. Persistent ductus arteriosus (PDA) defines a patent ductus arteriosus at seventy-two hours after birth $[8,9]$.

In "term infants," PDA occurs in 0.3-4/1000 live births at the end of the neonatal period, representing $5-10 \%$ of the congenital heart defects $[2,10,11]$. Sometimes PDA accompanies congenital ductal-dependent heart defects and closure of the PDA soon after birth may precipitate clinical deterioration [12]. In premature infants, PDA incidence is inversely associated with gestational age (GA) and birth weight (BW), the incidence varying between $20-70 \%$ in very low birth weight infants (VLBW) [3,6,8,13-20].

Multiple risk factors have been described in association with PDA such as lower GA and BW [14-16,21,22], chorioamnionitis and neonatal sepsis, [3,15,22-25], maternal diabetes mellitus, $[14,26]$ antepartum hemorrhage, multiple pregnancy, male gender [14], small for gestational age (SGA), [27] lower Apgar scores, need for resuscitation at birth, asphyxia [16], severe respiratory distress syndrome (RDS) [16,22,28,29], excessive fluid administration during the first days of life [30], Furosemide administration [31], decreased platelets number during the first day of life [22,32], oxygen administration [16], lower oxygen saturation targets $[33,34]$, surfactant administration $[16,28,35,36]$, increased duration of mechanical ventilation and respiratory support [22], metabolic acidosis [16], phototherapy [37], and high altitude [6].

In preterm infants, during the neonatal period, PDA is a multifactorial condition, most often concomitant with respiratory distress syndrome, often significantly affecting the haemodynamics and compromising blood flow and oxygenation with short and long-term consequences. In the short term, PDA is associated with decreased blood pressure [5,8], decreased renal function [5], cardiac congestive failure [18,37,38], pulmonary haemorrhage $[8,39]$, apnea and ventilator-dependency $[6,38]$, bronchopulmonary dysplasia (BPD) $[5,14,20,21,25,34,41,42]$, necrotizing enterocolitis (NEC) $[8,9,11,19,20,34,39,43,44]$, intraventricular hemorrhage (IVH) $[5,19,20,39,42,45,46]$, periventricular leukomalacia (PVL) [5], retinopathy of prematurity (ROP), cerebral palsy [24], delayed growth [11], and increased mortality rate $[6,34,45,47-50]$.

The aim of this study was to evaluate the association between the presence of PDA and the severity of the clinical condition in critically ill preterm infants with GA $\leq 32$ weeks and severe respiratory distress syndrome at birth.

\section{口 METHODS}

\section{Study population}

All preterm infants with GA $\leq 32$ weeks admitted to the neonatal intensive care unit (NICU) of the Clinical County Emergency Hospital Sibiu between 1 January 2010 and 31 December 2015 were included in the study. Epidemiological and clinical data were collected from the National Registry for RDS, which is a large Romanian registry that collects epidemiological data, information regarding RDS severity and treatment, and on short-term outcome in preterm infants with $\mathrm{GA} \leq 32$ weeks.

PDA was considered to exist if ductal flow was visualized by colour Doppler echocardiography after the 7th day of life, irrespective of its caliber and haemodynamic significance. The preterm infants included in the study were divided into two groups, according to the presence of PDA. Group 1 included patients with PDA $(\mathrm{n}=154)$, and Group 2 included patients without PDA $(n=186)$. Fifty-one preterm infants who did not survive to discharge (40 from the Group 1 and 11 from the Group 2) were excluded from the analysis, since deaths frequently occurred during the first days of life, before reaching the seven days necessary to define a PDA as a pathological condition.

The following data was extracted from the National Registry:

a) Data related to prenatal period - maternal prenatal conditions, pregnancy complications, antenatal corticosteroid administration, preterm rupture of the membranes, pregnancy type, delivery mode;

b) Clinical characteristics at birth - GA, BW, SGA, gender, Apgar scores at 1 and 5 minutes;

c) Clinical characteristics associated with the critical condition of the preterm infant: birth resuscitation and peripheral oxygen saturation during resuscitation at birth, surfactant administration, need and duration of respiratory support, neonatal sepsis, complications associated with prematurity (bronchopulmonary dysplasia, necrotizing enterocolitis, intraventricular hemorrhage, severe retinopathy of prematurity, neonatal sepsis), and death.

BPD was diagnosed if positive-pressure respiratory support with any fraction of inspired oxygen $\left(\mathrm{FiO}_{2}\right)$ or 
supplemental oxygen were needed at 36 weeks corrected age, since we used continuous positive air pressure (CPAP) with room air for weaning from mechanical ventilation and CPAP was stopped when the patients achieved respiratory stability. All other definitions used for neonatal conditions are based on the Vermont-Oxford Trials Network [51].

The study was conducted in accordance with the principles stipulated in the Declaration of Helsinki. All the subject parents agreed with processing of newborn data and all the study procedures were carried out following approval of the institution where the newborns were treated.

\section{Statistical analysis}

Data are reported as values, mean (SD), and percentages. SPSS 10.0 for Windows was used for data analysis. The independent t-test was used for scale variables while Fisher's exact test or chi-square test (where appropriate) were used for the analysis of categorial variables.

Statistical significance was set at $\alpha=0.05$. The odds ratio was calculated, and confidence intervals (CI) of 95\% were used.

\section{RESULTS}

During the study period, 391 preterm infants with $\mathrm{GA} \leq 32$ weeks were admitted in the neonatal intensive care unit of the Clinical County Emergency Hospital Sibiu, of whom 194 were diagnosed with PDA (49.6\%). From the 340 preterm infants who survived to day seven postpartum, 154 were diagnosed with PDA after the seventh day while in 186 infants, PDA was not identified by echocardiography. For the purpose of the study, data of the preterm infants surviving up to discharge was analyzed.

\section{A. Prenatal characteristics of the study populations}

The presence of PDA was associated with a decreased rate of prolonged rupture of the amniotic membranes and decreased gestational age at prenatal corticosteroid prophylaxis (Table 1). No significant differences were seen between infants with and without PDA as regards the presence and types of complications during pregnancy, pregnancy type, delivery mode, and antenatal corticosteroid therapy (Table 1).

\section{B. Clinical characteristics at birth in the study popu- lation}

The mean GA in Group 1 was significantly lower than the mean GA in Group $2(\mathrm{p}<0.0001)$ ], as was true the mean

Table 1. Maternal, pregnancy and delivery data

\begin{tabular}{|c|c|c|c|c|c|c|}
\hline & \multicolumn{2}{|c|}{ Group 1 (PDA) } & \multicolumn{2}{|c|}{ Group 2 (no PDA) } & \multirow{2}{*}{$\mathbf{p}$} & \multirow{2}{*}{$\mathrm{HR}[95 \% \mathrm{Cl}]$} \\
\hline & No. & Value & No. & Value & & \\
\hline \multicolumn{7}{|l|}{ Corticosteroid therapy } \\
\hline Prenatal corticosteroids ( $\mathrm{n} / \%$ ) & 154 & $82(53.2)$ & 186 & $104(55.9)$ & 0.624 & $0.89[0.58-1.38]$ \\
\hline Complete course (n/\%) & 82 & $49(59.2)$ & 104 & $73(70.2)$ & 0.138 & $0.63[0.34-1.16]$ \\
\hline Number of doses (mean \pm SD) & 82 & $2.6 \pm 1.3$ & 105 & $2.5 \pm 1.3$ & 0.699 & - \\
\hline $\begin{array}{l}\text { Time elapsed from initiation of corticosteroid } \\
\text { prophylaxis to delivery (hours) (mean } \pm \text { SD) }\end{array}$ & 82 & $11.4 \pm 22.1$ & 104 & $15.6 \pm 34.4$ & 0.341 & - \\
\hline \multicolumn{7}{|l|}{ Complications during pregnancy } \\
\hline Any complication (n/\%) & 154 & $33(21.4)$ & 186 & $35(18.8)$ & 0.550 & $1.18[0.69-2.00]$ \\
\hline Diabetes mellitus (n/\%) & 154 & $0(0)$ & 186 & $1(0.5)$ & - & - \\
\hline Antenatal hemorrhage (n/\%) & 154 & $6(3.9)$ & 186 & $3(1.6)$ & 0.193 & $2.47[0.61-10.06]$ \\
\hline Pregnancy-induced hypertension (n/\%) & 154 & $10(6.5)$ & 186 & $13(7.0)$ & 0.857 & $0.92[0.39-2.17]$ \\
\hline Eclampsia (n/\%) & 154 & $0(0)$ & 186 & $4(2.2)$ & - & - \\
\hline Chorioamnionitis (n/\%) & 154 & $0(0)$ & 186 & $4(2.2)$ & - & - \\
\hline \multicolumn{7}{|l|}{ Type of pregnancy } \\
\hline Multiple pregnancy (n/\%) & 154 & $48(31.2)$ & 186 & $44(23.7)$ & 0.121 & $1.46[0.90-2.36]$ \\
\hline Second twin (n/\%) & 48 & $29(60.4)$ & 44 & $25(56.8)$ & 0.730 & $1.16[0.50-2.66]$ \\
\hline ART pregnancy $(\mathrm{n} / \%)$ & 154 & $9(5.8)$ & 186 & $6(3.2)$ & 0.243 & $1.86[0.65-5.35]$ \\
\hline \multicolumn{7}{|l|}{ Delivery } \\
\hline Rupture of the amniotic membranes $>18$ hours (n/\%) & 154 & $28(18.2)$ & 186 & $52(28.0)$ & 0.034 & $0.57[0.34-0.96]$ \\
\hline Cesarean section (n/\%) & 154 & $48(31.2)$ & 186 & $48(25.8)$ & 0.276 & $1.30[0.81-2.09]$ \\
\hline
\end{tabular}


BW $[p<0.0001)] \quad$ (Table 2). No significant differences were seen between Group 1 and Group 2 with regards to gender, ponderal index, and SGA status (Table 2).

Group 1 had lower Apgar scores at one and ten minutes, but no significant difference was found between groups regarding the need for resuscitation at birth (Table 3). Interestingly, despite having similar mean peripheral oxygen saturations during resuscitation, Group 2 infants received significantly increased oxygen concentrations at birth (Table 3 ).

\section{Severity of the clinical condition in the critically ill preterm infants}

The severity of RDS was increased in Group 1 as compared to Group 2. Group 1 presented a significantly higher need for surfactant administration $(p<0.0001)$ and respiratory support $[\mathrm{p}=0.019]$, and Continuous
Positive Airways Pressure (CPAP) and mechanical ventilation [ $p=0.004$ ] Duration of respiratory support was also significantly increased in the Group 1 for CPAP and for mechanical ventilation. $\mathrm{p}<0.0001$ ) (Table 3 ).

Premature infants in Group1 had significantly increased rates of bronchopulmonary dysplasia (BPD) $(\mathrm{p}=0.002$, HR 2.94), intraventricular hemorrhage (IVH) $(\mathrm{p}=0.050, \mathrm{HR} 1.56)$, and severe retinopathy of prematurity $(\mathrm{ROP})(\mathrm{p}=0.056)$. No significant associations were found between PDA and neonatal sepsis and necrotizing enterocolitis (NEC). The presence of PDA was also associated with a significantly increased rate of death $(20.6 \%$ vs. $5.6 \%, p<0.0001$, HR 4.39$)$. No difference was found between the study groups as regards necrotizing enterocolitis, periventricular leukomalacia, or severe retinopathy of prematurity. Both early and late onset sepsis were recorded to a greater extent in

Table 2. Neonatal characteristics

\begin{tabular}{|c|c|c|c|c|c|c|}
\hline & \multicolumn{2}{|c|}{ Group 1 (PDA) } & \multicolumn{2}{|c|}{ Group 2 (no PDA) } & \multirow[t]{2}{*}{$\mathbf{p}$} & \multirow[t]{2}{*}{$\mathrm{HR}[95 \% \mathrm{Cl}]$} \\
\hline & No. & Value & No. & Value & & \\
\hline Gestational age (weeks) (mean \pm SD) & 154 & $29.7 \pm 2.0$ & 186 & $30.4 \pm 1.7$ & 0.0001 & - \\
\hline Birthweight (g) (mean $\pm S D)$ & 154 & $1297.4 \pm 327.6$ & 186 & $1458.0 \pm 317.4$ & 0.0001 & - \\
\hline Male gender (n/\%) & 154 & $86(55.8)$ & 186 & $101(54.3)$ & 0.777 & $1.06[0.69-1.63]$ \\
\hline Ponderal index (mean $\pm S D)$ & 154 & $1.96 \pm 0.33$ & 186 & $1.95 \pm 0.32$ & 0.596 & - \\
\hline SGA (n/\%) & 154 & $84(54.5)$ & 186 & $102(54.8)$ & 0.957 & $0.99[0.64-1.52]$ \\
\hline
\end{tabular}

Table 3. Neonatal status at delivery and respiratory distress syndrome

\begin{tabular}{|c|c|c|c|c|c|c|}
\hline & \multicolumn{2}{|c|}{ Group 1 (PDA) } & \multicolumn{2}{|c|}{ Group 2 (no PDA) } & \multirow[t]{2}{*}{$\mathbf{P}$} & \multirow[t]{2}{*}{$\operatorname{HR}[95 \% \mathrm{Cl}]$} \\
\hline & No. & Value & No. & Value & & \\
\hline \multicolumn{7}{|l|}{ Birth resuscitation } \\
\hline Need for resuscitation at birth (n/\%) & 154 & $98(63.6)$ & 186 & $121(65.1)$ & 0.787 & $0.94[0.60-1.74]$ \\
\hline FiO2 during resuscitation (\%) (mean \pm SD) & 98 & $84.8 \pm 29.7$ & 121 & $92.5 \pm 22.8$ & 0.030 & - \\
\hline Peripheral oxygen saturation during resuscitation & 93 & $88.1 \pm 4.9$ & 106 & $89.0 \pm 5.3$ & 0.221 & - \\
\hline Apgar scores at 1 minute (mean $\pm S D$ ) & 151 & $6.3 \pm 2.0$ & 185 & $6.7 \pm 1.8$ & 0.022 & - \\
\hline Apgar scores at 5 minutes (mean \pm SD) & 146 & $7.6 \pm 1.4$ & 178 & $7.8 \pm 1.1$ & 0.087 & - \\
\hline Apgar scores at 10 minutes (mean \pm SD) & 140 & $8.0 \pm 0.9$ & 164 & $8.4 \pm 0.7$ & 0.0001 & - \\
\hline Apgar scores at 20 minutes (mean \pm SD) & 28 & $8.2 \pm 0.6$ & 68 & $8.2 \pm 0.7$ & 0.880 & - \\
\hline \multicolumn{7}{|l|}{ Respiratory distress syndrome management } \\
\hline Need for surfactant administration (n/\%) & 154 & 66 (42.9) & 186 & $46(24.7)$ & 0.0001 & $2.28[1.44-3.62]$ \\
\hline Surfactant dose (mg/kg)(mean $\pm S D)$ & 66 & $166.4 \pm 33.6$ & 46 & $171.8 \pm 31.5$ & 0.398 & - \\
\hline INSURE strategy (n/\%) & 154 & $51(33.1)$ & 186 & $35(18.8)$ & 0.002 & $2.14[1.30-3.51]$ \\
\hline Need for oxygen therapy (n/\%) & 154 & 139 (90.3) & 186 & $168(90.8)$ & 0.863 & $0.94[0.45-1.94]$ \\
\hline Oxygen therapy length (days) (mean $\pm S D$ ) & 139 & $19.0 \pm 34.5$ & 168 & $8.4 \pm 14.5$ & 0.0001 & - \\
\hline Need for CPAP (n/\%) & 154 & 149 (96.8) & 186 & $168(90.3)$ & 0.019 & $3.19[1.16-8.81]$ \\
\hline CPAP support duration (days) (mean \pm SD) & 149 & $7.6 \pm 7.5$ & 169 & $5.1 \pm 3.8$ & 0.0001 & - \\
\hline Need for mechanical ventilation (n/\%) & 154 & $34(22.1)$ & 168 & $20(10.8)$ & 0.004 & $2.35[1.29-4.29]$ \\
\hline $\begin{array}{l}\text { Duration of mechanical ventilation (days) } \\
\text { (mean } \pm \text { SD) }\end{array}$ & 34 & $20.1 \pm 22.5$ & 20 & $12.0 \pm 15.7$ & 0.0001 & - \\
\hline
\end{tabular}


Table 4. Complications during hospitalization

\begin{tabular}{lcccccc} 
& \multicolumn{2}{c}{ Group $\mathbf{1}$ (PDA) } & \multicolumn{2}{c}{ Group 2 (no PDA) } & p & HR [95\% Cl] \\
& No. & Value & No. & Value & & \\
Bronchopulmonary dysplasia (n/\%) & 154 & $26(16.9)$ & 186 & $12(6.5)$ & 0.002 & $2.94[1.43-6.06]$ \\
Necrotizing enterocolitis (n/\%) & 154 & $3(1.9)$ & 186 & $1(0.5)$ & 0.231 & $3.67[0.38-3.57]$ \\
Intraventricular hemorrhage (n/\%) & 154 & $62(40.3)$ & 186 & $56(30.1)$ & 0.050 & $1.56[0.99-2.45]$ \\
Periventricular leukomalacia (n/\%) & 154 & $6(3.9)$ & 186 & $4(2.2)$ & 0.344 & $1.84[0.51-6.66]$ \\
Severe retinopathy of prematurity (n/\%) & 154 & $3(1.9)$ & 186 & $0(0)$ & 0.056 & - \\
Early onset sepsis (n/\%) & 154 & $25(16.2)$ & 186 & $20(10.8)$ & 0.138 & $1.61[0.85-3.02]$ \\
Late onset sepsis (n/\%) & 154 & $21(13.6)$ & 186 & $27(14.5)$ & 0.817 & $0.93[0.50-1.72]$ \\
Any infection (n/\%) & 154 & $46(29.8)$ & 186 & $47(25.2)$ & 0.831 & $1.05[0.65-1.70]$ \\
Hospitalization length (days) (meantSD) & 154 & $52.9 \pm 26.4$ & 186 & $44.1 \pm 18.5$ & 0.0001 & - \\
Death (n/\%) & 194 & $40(20.6)$ & 197 & $11(5.6)$ & 0.0001 & $4.39[2.18-8.85]$ \\
\hline
\end{tabular}

the Group 1 than Group 2 (16.2\% vs. $10.8 \%$ for early onset sepsis and $13.6 \%$ vs. $14.5 \%$ for late-onset sepsis). However, the differences were not statistically different. The presence of PDA was also associated with a significantly increased rate of death in Group 1 than Group 2 $(\mathrm{p}<0.0001)$, (Table 4).

\section{Discussions}

In preterm infants, PDA is diagnosed significantly more often than in term infants, $40-60 \%$ according to gestational age in preterm infants $[17,18,49]$ versus $57 / 10.000$ live births in term infants [7,20], and is associated with considerably increased morbidity and mortality [14]. Functional closure of DA in preterm infants with $\mathrm{GA} \geq 30$ weeks gestation occurs towards the fourth day of life, while in those with $\mathrm{GA}<30$ weeks or with RDS the incidence of PDA is about $65 \%$ [5,19,51]. Instead of analyzing only infants with significant PDA we have chosen to define and analyze PDA only if the ductus was seen on echocardiography after the first week of life. Therefore, the incidence reported in our study corresponds to data reported in the literature.

Patent ductus arteriosus, associated risk factors and clinical presentation at birth in very preterm infants

Among the factors significantly influencing the persistence of DA, GA is the most often cited. [3,6,13$16,20,21,52]$ Koch et al. [19] evaluated the direct relationship between GA and spontaneous closure of DA showing that for each gestational week after 23 weeks, the odds for spontaneous closure of the ductus increases with a ratio of 1.5 . Studies also demonstrate that the incidence of PDA increases with a decrease in
BW $[3,6,13-16,19,24,42,43,52,53]$. In our study, in accordance with published data, infants with PDA had significantly lower mean BW and GA $(\mathrm{p}<0.05)$.

Male gender was reported by Hammoud et al. as a risk factor for PDA. However, in accord with Nizarali et al. the current results found no difference between the study groups regarding gender [14,16]. Nor was any difference found between infants with and without PDA when comparing the mean ponderal index and the proportions of SGA infants even though SGA was reported in other studies as a risk factor for PDA $[27,49]$.

Prenatal corticosteroid prophylaxis decreases the risk for PDA [14,16,49,54,55], even if administered after chorioamnionitis [24]. In the present study, similar proportions of infants with and without PDA received prenatal corticosteroids, and even if more infants received a complete course, the difference between the two groups was not significant $p>0.050$. This may also be explained by the similar mean number of corticosteroid doses and by the insignificant difference between mean time elapsed from prophylaxis initiation to delivery.

Diabetes mellitus was reported by Hammoud et al. as a risk factor for PDA in preterm infants aged $<34$ weeks gestation [14]. They also found that antepartum haemorrhage occurred more often in premature infants with PDA. Many studies linked chorioamnionitis to PDA in preterm infants $[3,15,23-25,56]$. In these cases, inflammation increases cyclo-oxygenase activity and prostaglandin E2 production causing PDA [56]. Pregnancy-induced hypertension and eclampsia are associated with decreased incidence of PDA as these conditions are characterized by accelerated pulmonary 
maturation $[14,15,57]$. We have found no difference between preterm infants with and without PDA when analyzing the complications during pregnancy: diabetes mellitus, antenatal hemorrhage, pregnancy-induced hypertension, eclampsia, and clinical chorioamnionitis. Most probably these results are due to the small number of complications noted in the present study. Also, only cases of clinical chorioamnionitis were considered, as data regarding histological amnionitis were not available. In a meta-analysis comprising 23 studies and 17.708 preterm infants, Park et al. showed a lack of association between PDA and clinical chorioamnionitis [24].

The study performed by Hammoud et al. was the only one found that reported an association between PDA and multiple pregnancies [14]. They indicated that a multiple pregnancy has four times the risk of PDA. We also found PDA more often in preterm infants from multiple pregnancies, 31.2 versus $23.7 \%$, but the difference was not significant. The PDA incidence was similar in the second twin in both study groups.

No information was found in the literature with regards to associations between PDA and assisted reproductive techniques or delivery mode. The current study data shows that very preterm infants conceived using assisted reproductive techniques may have an increased incidence of PDA compared to those naturally conceived $(p>0.05)$. In larger preterm infants, delivery by cesarean section is associated with an increased risk of PDA [58]. A similar trend was seen in our groups of very preterm infants, but the difference was not statistically significant. A more detailed analysis of the reasons for performing cesarean section may reveal why PDA is more often seen in preterm infants delivered by cesarean section compared to vaginal birth.

Hypoxia and low Apgar scores were associated with increased incidence of PDA $[16,59]$. Compared to preterm infants without PDA, Group1 compared to Group 2 in the present study had significantly lower mean Apgar scores at 1 and 10 minutes, lower scores at $5 \mathrm{~min}$ utes, and similar scores at twenty minutes.

\section{Patent ductus arteriosus and resuscitation at birth in very preterm infants}

The need for resuscitation at birth was cited by Nizarali et al. as a risk factor for PDA [16]. There was no difference between Group 1 and Group 2 with regards to the need for resuscitation at birth. This may be due to the continuous change of the resuscitation protocols, according to national and international guidelines, which occurred, during the study period, acceptance of lower oxygen saturations in the first minutes of life, and more extensive use of positive pressure ventilation with T-piece resuscitator in very preterm infants [60]. Nevertheless, we noted that infants without PDA after the first week of life were resuscitated at birth with significantly increased oxygen concentrations $(\mathrm{p}=0.030)$ while no difference was seen between the mean peripheral oxygen saturation. It can be speculated that increased $\mathrm{FiO}_{2}$ during resuscitation may have triggered PDA closure since increased arterial oxygen pressure is one of the most important factors contracting DA [4].

\section{Respiratory distress syndrome and patent ductus arteriosus in very preterm infants}

In very preterm infants, one of the most important risk factors for PDA, cited in the literature, is RDS. Pegoli reported a PDA incidence of $80 \%$ in preterm infants with RDS and Smith [6] hypothesized that increased circulating prostaglandin E2 concentrations during RDS are responsible for ductus arteriosus persistence $[61,62]$. In agreement with data reported by other authors, the need for surfactant administration, which is taken to reflect the severity of RDS, was significantly increased in preterm infants with PDA after the first week of life $(\mathrm{p}=0.000),[16,28,35,36,49]$. According to Clyman et al. surfactant alters pulmonary vascular resistance, favouring early left-to-right shunting through the DA [49]. No difference was found between the mean doses of surfactant administered $(p=0.398)$ between the study groups. The increased proportion of preterm infants with PDA treated using the INSURE strategy (INtubate-SURfactant-Extubate on CPAP) is explained only by the appliance of national and European guidelines for RDS treatment recommending a non-invasive approach in preterm infants that do not require assisted ventilation at birth. Similarly, according with current recommendations, a very high proportion of the preterm infants in both study groups were treated using CPAP support, (Table 3) and an increased proportion of infants with PDA needed mechanical ventilation $(\mathrm{p}=0.004)$, and mean duration of oxygen therapy, CPAP support, and mechanical ventilation were significantly increased compared to premature infants without PDA $(\mathrm{p}<0.05)$ demonstrating that increased severity of RDS is associated with higher risk for PDA after the seventh day of life $[16,21,22,60,63]$ (Table 3). 
Numerous studies have demonstrated that PDA significantly influences morbidity and mortality of the very preterm infants. $[6,11,43,45,47,63]$. In the short term, PDA is associated with arterial hypotension, myocardial dysfunction and systemic perfusion $[5,8,38]$, renal functional disturbances $[5,19,39]$, and pulmonary hemorrhage $[40,64,65]$.

As in other studies the current data showed a significant association between PDA and BPD $(\mathrm{p}=0.002)$ (Table 4) $[6,9,15,20,21,25,41,42,47,66-69]$. An almost similar risk was reported by Marshall et al. in VLBW infants (BW <1500 g) [69]. In preterm infants with RDS, PDA induces an interstitial and alveolar pulmonary edema, decreases pulmonary compliance, increases the need and length of mechanical ventilation and oxygen needs, thus increasing the risk for BPD $[5,42]$.

\section{Patent ductus arteriosus and necrotizing enterocol- itis in very preterm infants}

Ductus arteriosus persistence was also associated with an increased risk of NEC in very preterm infants, and other studies $[11,21,43,44,47,70]$. The current study also showed an increased incidence of NEC in preterm infants $\leq 32$ weeks gestation, but the low number of NEC cases may explain the lack of significance of this association (Table 4). Predisposition to NEC in preterm infants with PDA is due to diastolic blood stealing from the superior mesenteric artery and abdominal aorta through DA with secondary intestinal hypoperfusion $[5,42,43]$.

Patent ductus arteriosus, intraventricular hemorrhage and periventricular leukomalacia in very preterm infants

A significant PDA also affects the cerebral blood flow, mostly during diastole, a possible pathway for IVH and PVL $[42,46]$. A link between PDA and IVH has been reported in many studies, as in the current report where there was an increased risk for IVH in Group 1 compared to Group $2[20,40,46,47,68]$ (Table 4).

\section{Patent ductus arteriosus and severe retinopathy of prematurity in very preterm infants}

Only one study reporting a significant association between PDA and ROP was found in the literature, but after adjusting for GA, the association was attributed only to GA [72]. Only three preterm infants with severe ROP needed laser therapy during the current study period. Since the mean GA and BW were significantly lower in Group 1, it may be concluded that GA and BW are important contributory factors.

\section{Patent ductus arteriosus and sepsis in very preterm infants}

Even though some authors reported an increased incidence of PDA in preterm infants with early and late neonatal infections, no correlation between the incidence of PDA and neonatal infections even if early and late infections were aggregated, $(\mathrm{p}>0.05)$ despite the fact that higher proportions of preterm infants with PDA developed early neonatal sepsis and any neonatal sepsis [3,25] (Table 4).

\section{Mortality associated with patent ductus arteriosus in very preterm infants}

The death rate is significantly increased in preterm infants with PDA, increasing with decreasing GA and in association with lack of antenatal corticosteroid prophylaxis [53].

This is a similar risk of death in preterm infants $\leq 32$ weeks gestation with PDA after the first week of life and a significantly increased mean duration of hospitalization, $(\mathrm{p}<0.05)$ as reported in the current study (Table 4). Significantly lower GA, BW, more severe RDS, more frequent severe complications of prematurity, BPD, NEC, IVH, ROP, are significant contributors to the increased rate of death and prolonged hospitalization and PDA was associated with all these factors in our study.

\section{Considerations related to study protocol}

The classic definition of PDA implies failed closure of DA after 72 hours of life [8,9]. Most of the studies in the literature evaluated risk factors only haemodynamically significant PDA and its influence on neonatal morbidity and mortality. We have chosen to evaluate the clinical and pathological correlations of PDA after the first week of life, regardless of size and hemodynamic influence, in very preterm infants ( $\leq 32$ weeks gestation). However, we have found the same clinical associations, lower GA and BW, lower Apgar scores, severe $\mathrm{RDS}$ including need for surfactant administration and respiratory support, prolonged oxygen therapy and respiratory support (both CPAP and mechanical ventilation) - and pathological correlations - BPD, IVH, severe ROP, and death - as demonstrated by others in evaluating hemodynamically significant PDA in very preterm infants. 
In agreement with previous studies the current study reported, in very preterm infants, the same clinical associations, i.e. lower GA and BW, lower Apgar scores, severe RDS the need for surfactant administration and respiratory support, prolonged oxygen therapy and respiratory support, with pathological states i.e. - BPD, IVH, severe ROP, and death.

More studies are needed, most probably stratified on gestational age, to identify the most important risk factors for each GA and to develop more successful management strategies, to more clearly define which preterm infants need treatment, the best moment for therapeutic interventions, and the best therapeutic approach for a better long-term outcome. Interventional strategies for prevention of unfavorable outcome of PDA in very preterm critically ill infants must also focus on clinical and pathological correlations of PDA not only on PDA prophylaxis and therapy.

\section{- CONCLUSIONS}

In very preterm infants, delivered at $\leq 32$ gestational weeks, PDA can be associated with a critical clinical condition leading to serious complications. The presence of PDA after the 7th day of life is associated with an increased need for respiratory support, both by CPAP and mechanical ventilation and an increased severity of the respiratory distress syndrome, requiring a longer duration of respiratory support and prolonging the hospitalization length. In very preterm infants, PDA is also associated with significantly higher rates of severe prematurity associated complications and death, indicating the need for a careful and appropriate management of these critical cases in the neonatal intensive care units.

\section{DISCLOSURE OF CONFLICTS OF INTEREST}

None to declare

\section{REFERENCES}

1. Kaemmerer H, Meisner H, Hess J, Perloff JK. Surgical treatment of patent ductus arteriosus: a new historical perspective. Am J Cardiol. 2004;94:1153-4.

2. Schneider DJ, Moore JW. Patent Ductus Arteriosus. Circulation 2006;114:1873-82. DOI: 10.1161/ CIRCULATIONAHA.105.592063.

3. Hillman M, Meinarde L, Rizzotti A, Cuestas E. Inflammation, High-sensitivity C-reactive Protein, and Persistent Patent
Ductus Arteriosus in Preterm Infants. Rev Esp Cardiol (Engl Ed). 2016;69:84-5. doi: 10.1016/j.rec.2015.09.014.

4. Al Nemri AMH. Patent ductus arteriosus in preterm infant: Basic pathology and when to treat. Sudan J Paediatr. 2014;14:25-30.

5. Abdel-Hady H, Nasef N, Shabaan AE, Nour I. Patent Ductus Arteriosus in Preterm Infants: Do We Have the Right Answers? BioMed Research International 2013. http://dx.doi. org/10.1155/2013/676192.

6. Dice JE, Bhatia J. Patent Ductus Arteriosus: An Overview. J Pediatr Pharmacol Ther. 2007;12:138-46. doi: 10.5863/15516776-12.3.138

7. Fanos V, Pusceddu M, Dessi A, Marcialis MA. Should we definitively abandon prophylaxis for patent ductus arteriosus in preterm new-borns? Clinics. 2011;66:2141-9. http://dx.doi. org/10.1590/S1807-59322011001200022.

8. Hermes-DeSantis ER, Clyman RI. Patent ductus arteriosus: pathophysiology and management. J Perinatol. 2006;26:S148. DOI: 10.1038/sj.jp.7211465

9. Clyman RI. Ibuprofen and patent ductusarteriosus. NEngIJ Med. 2000;343:728-39. DOI: 10.1056/NEJM200009073431009

10. Hoffman JI, Kaplan S. The incidence of congenital heart disease. J Am Coll Cardiol. 2002;39:1890-900.

11. Fortescue EB, Lock JE, Galvin T, McElhinney DB. To Close or Not to Close: The Very Small Patent Ductus Arteriosus. Congenit Heart Dis. 2010;5:354-65. doi: 10.1111/j.17470803.2010.00435.x.

12. Toganel R. Critical Congenital Heart Diseases as Lifethreatening Conditions in the Emergency Room. Journal of Cardiovascular Emergencies. 2016;2:7-10. DOI: 10.1515/jce2016-0002.

13. Feng YS, Yu V. Management of Patent Ductus Arteriosus in Very Preterm Infants in the Post-surfactant Era. HK J Paediatr (new series). 2003;8:93-100.

14. Hammoud MS, Elsori HA, Hanafi E-AM, Shalabi AA, Fouda IA, Devarajan LV. Incidence and risk factors associated with the patency of ductus arteriosus inpreterm infants with respiratory distress syndrome in Kuwait. Saudi Med J. 2003;24:982-5.

15. Lee JA, Kim M-J, Oh S, Choi BM. Current Status of Therapeutic Strategies for Patent Ductus Arteriosus in Very-Low-BirthWeight Infants in Korea. J Korean Med Sci. 2015;30:S59-66. doi: 10.3346/jkms.2015.30.S1.S59.

16. Nizarali Z, Marques T, Costa C, Barroso R, Cunha M. Patent Ductus Arteriosus: Perinatal Risk Factors. J Neonatal Biol. 2012;1:3. http://dx.doi.org/10.4172/2167-0897.1000109.

17. Evans N. Preterm patent ductus arteriosus: should we treat it? J Paediatr and Child Health. 2012;48:753-8. doi: 10.1111/j.1440-1754.2012.02542.x.

18. Meyer S. PDA in neonates-please doctor act individually! Acta Paediatr. 2012;101:e145-6. DOI: 10.1111/j.16512227.2012.02617.x.

19. Koch J, Hensley G, Roy L, Brown S, Ramaciotti C, Rosenfeld CR. 
Available online at: www.jccm.ro

Prevalence of spontaneous closure of the ductus arteriosus in neonates at a birth weight of 1000 grams or less. Pediatrics. 2006;117:1113-21. DOI: 10.1542/peds.2005-1528.

20. Hamrick SE, Hansmann G. Patent ductus arteriosus of the preterm infant. Pediatrics. 2010;125:1020-30. doi: 10.1542/ peds.2009-3506.

21. Chen $H-L$, Yang $R-C$, Lee $W-T$, et al. Lung function in very preterm infants with patent ductus arteriosus under conservative management: an observational study. BMC Pediatrics. 2015;15:167. DOI: 10.1186/s12887-015-0480-y.

22. Du J-F, Liu T-T, Wu H. Risk factors for patent ductus arteriosus in early preterm infants: a case-control study. Zhongguo Dang Dai Er Ke Za Zhi. 2016;18:15-9.

23. Garcla-Munoz RF, Galan HG, Figueras AJ, Garcla-Alix PA. Outcomes of very-low-birth-weight infants exposed to maternal clinical chorioamnionitis: a multicentre study. Neonatology 2014;106:229-34. doi: 10.1159/000363127.

24. Park HW, Choi Y-S, Kim KS, Kim S-N. Chorioamnionitis and Patent Ductus Arteriosus: A Systematic Review and MetaAnalysis. PLoS ONE. 2015;10:e0138114. doi: 10.1371/journal. pone.0138114.

25. Gonzalez A, Sosenko IR, Chandar J, et al. Influence of infection on patent ductus arteriosus and chronic lung disease in premature infants weighing 1000 grams or less. J Pediatr. 1996;128:470-8.

26. Seppanen MP, Ojanpera OS, Kaapa PO, Kero PO. Delayed postnatal adaptation of pulmonary hemodynamics in infants of diabetic mothers. J Pediatr. 1997;131:545-8.

27. Rakza T, Magnenant E, Klosowski S, Tourneux P, Bachiri A, Storme L. Early hemodynamic consequences of patent ductus arteriosus in preterm infants with intrauterine growth restriction. J Pediatr. 2007;151:624-8. DOI: 10.1016/j. jpeds.2007.04.058.

28. Agarwal R, Deorari AA, Paul VK. Patent Ductus Arteriosus in Preterm Neonates. Indian J Pediatr. 2008;75:277. doi: 10.1007/s12098-008-0059-9.

29. Saeidi R, Mahmoodi E, Eslami M, Gholami M. Evaluation of Risk Factors Related with Neonatal Patent Ductus Arteriosus in Hospitalized Neonates of Neonatal Intensive Care Unit. Zahedan J Res Med Sci (ZJRMS). 2012;14:33-5.

30. Bell EF, Acarregui MJ. Restricted versus liberal water intake for preventing morbidity and mortality in preterm infants. Cochrane Database Syst Rev. 2008;(1):CD000503. doi: 10.1002/14651858.CD000503.pub2.

31. Green TP, Thompson TR, Johnson DE, Lock JE. Furosemide promotes patent ductus arteriosus in premature infants with the respiratory distress syndrome. N Engl J Med. 1983;308:743-8.

32. Simon SR, van Zogchel L, Bas-Suárez MP, Cavallaro G, Clyman RI, Villamor E. Platelet Counts and Patent Ductus Arteriosus in Preterm Infants: A Systematic Review and Meta-Analysis. Neonatology. 2015;108:143-51. doi: 10.1159/000431281.

33. Shimada S, Kasai T, Hoshi A, Murata A, Chida S. Cardiocirculatory
The Journal of Critical Care Medicine 2016;2(4) • 183

effects of patent ductus arteriosus in extremely low-birthweight infants with respiratory distress syndrome. Pediatr Int. 2003;45:255-62.

34. Noori S, Patel D, Friedlich P, Siassi B, Seri I, Ramanathan R. Effects of low oxygen saturation limits on the ductus arteriosus in extremely low birth weight infants. J Perinatol. 2009;29:553-7. doi: 10.1038/jp.2009.60.

35. Kaapa P, Seppanen M, Kero P, Saraste M. Pulmonary hemodynamics after synthetic surfactant replacement in neonatal respiratory distress syndrome. J Pediatr. 1993;123:115-9.

36. Soll R, Özek E. Prophylactic protein free synthetic surfactant for preventing morbidity and mortality in preterm infants. Cochrane Database Syst Rev. 2010;(1):CD001079. doi: 10.1002/14651858.CD001079.pub2.

37. Rosenfeld W, Sadhev S, Brunot V, Jhaveri R, Zabaleta I, Evans HE. Phototherapy effect on the incidence of patent ductus arteriosus in premature infants: prevention with chest shielding. Pediatrics. 1986;78:10-4.

38. Sadecka LSR, Leoneb CR, Procianoyc RS, et al. Effects of therapeutic approach on the neonatal evolution of very low birth weight infants with patent ductus arteriosus. J Pediatr (Rio J). 2014 ;90:616-23. doi: 10.1016/j.jped.2014.04.010.

39. Hajjar ME, Vaksmann G, Rakza T, Kongolo G, Storme L. Severity of the ductal shunt: a comparison of different markers. Arch Dis Child Fetal Neonatal Ed. 2005;90:F419-22. DOI: 10.1136/ adc.2003.027698.

40. Kluckow M, Evans N. Ductal shunting, high pulmonary blood flow, and pulmonary hemorrhage. J Pediatr. 2000;137:68-72.

41. Mosalli R, Alfaleh K. Prophylactic surgical ligation of patent ductus arteriosus for prevention of mortality and morbidity in extremely low birth weight infants. Cochrane Database Syst Rev. 2008;(1):CD006181. doi: 10.1002/14651858.CD006181. pub2.

42. Noori S. Patent ductus arteriosus in the preterm infant: to treat or not to treat? J Perinatol. 2010;30 Suppl:S31-7. doi: 10.1038/jp.2010.97.

43. Dollberg S, Lusky A, Reichman B. Patent ductus arteriosus, indomethacin and necrotizing enterocolitis in very low birth weight infants: a population-based study. J Pediatr Gastroenterol Nutr. 2005;40:184-8.

44. McPherson C, Gal P, Smith M, et al. Necrotizing Entrocolitis and Intestinal Perforation in Preterm Infants with Patent Ductus Arteriosus: Does indomethacin increase the risk? Journal of Neonatal-Perinatal Medicine. 2008;1:209-16.

45. Sellmer A, Bjerre JV, Schmidt MR, et al. Morbidity and mortality in preterm neonates with patent ductus arteriosus on day 3. Arch Dis Child Fetal Neonatal Ed. 2013;98:F505-10. doi: 10.1136/archdischild-2013-303816.

46. Evans N, Kluckow M. Early ductal shunting and intraventricular haemorrhage in ventilated preterm infants. Arch Dis Child Fetal Neonatal Ed. 1996;75:F183-6.

47. Noori S, McCoy M, Friedlich P, et al. Failure of ductus 
184 The Journal of Critical Care Medicine 2016;2(4)

arteriosus closure is associated with increased mortality in preterm infants. Pediatrics. 2009;123:e138-44. doi: 10.1542/ peds.2008-2418.

48. Benitz WE. Treatment of persistent patent ductus arteriosus in preterm infants: time to accept the null hypothesis? J Perinatol. 2010;30:241-52. doi: 10.1038/jp.2010.3.

49. Clyman RI, Couto J, Murphy GM. Patent ductus arteriosus: are current neonatal treatment options better or worse than no treatment at all? Semin Perinatol. 2012;36:123-9. doi: 10.1053/j.semperi.2011.09.022.

50. Ivey KN, Srivastava D. The paradoxical patent ductus arteriosus. J Clin Invest. 2006;116:2863-5. Doi: 10.1172/JCI30349.

51. Vermont-Oxford trials network database project. Manual of Operations, Release 2.0. Neonatal Research and Technology Assessment, Inc. Burlington, 1993.

52. Nemerofsky SL, Parravicini E, Bateman D, Kleinman C, Polin RA, Lorenz JM. The ductus arteriosus rarely requires treatment in infants > 1000 grams. Am J Perinatol. 2008;25:661-6. doi: 10.1055/s-0028-1090594.

53. Fanaroff AA, Hack M, Walsh MC. The NICHD Neonatal Research Network: changes in practice and outcomes during the first 15 years. Semin Perinatol. 2003;27:281-7.

54. Popat H, Kapoor V, Travadi J. Patent Ductus Arteriosus in Infants <29 Weeks Gestation-Outcomes and Factors Affecting Closure. Indian Pediatr. 2012;49:615-20.

55. Eronen M, Kari A, Pesonen E, Hallman M. The effect of antenatal dexamethazone administration on the fetal and neonatal ductus arteriosus. A randomized double-blind study. Am J Dis Child. 1993;147:187-92.

56. Halliday HL, Ehrenkranz RA, Doyle LW. Early (<8 days) postnatal corticosteroids for preventing chronic lung disease in preterm infants. Cochrane Database Syst Rev. 2009;(1):CD001146. doi: 10.1002/14651858.CD001146.pub2.

57. Kim ES, Kim EK, Choi CW, et al. Intrauterine inflammation as a risk factor for persistent ductus arteriosus patency after cyclooxygenase inhibition in extremely low birth weight infants. J Pediatr. 2010;157:745-50.e1. doi: 10.1016/j. jpeds.2010.05.020.

58. Shah DM, Shenai JP, Vaughn WK. Neonatal outcome of premature infants of mothers with preeclampsia. J Perinatol. 1995;15:264-7.

59. Tsai M-L, Lien R, Chiang M-C, et al. Prevalence and Morbidity of Late Preterm Infants: Current Status in a Medical Center of Northern Taiwan. Pediatr Neonatol. 2012;53:171-7. doi: 10.1016/j.pedneo.2012.04.003.

60. Ognean ML, Stoicescu SM, Boanta O, Nastase L, Gliga C, Cucerea M. Intubation-Surfactant: Extubation on Continuous
Available online at: www.jccm.ro

Positive Pressure Ventilation. Who are the best candidates? J Crit Care Med. 2016;2:73-9. DOI: 10.1515/jccm-2016-0010.

61. Pegoli W. Pericardium and great vessels. In: Oldham KT, Colombiani PM, et al. (eds). Principles and Practice of Pediatric Surgery. 4th ed. Philadelphia, PA: Lippincott Williams \& Wilkins 2005; 1019.

62. Smith GC. The pharmacology of the ductus arteriosus. Pharmacol Rev. 1998;50:35-58.

63. Sweet Dg, Carnielli V, Greisen G, et al. European consensus guidelines on the management of neonatal respiratory distress syndrome in preterm infants--2013 update. Neonatology. 2013;103:353-68. doi: 10.1159/000349928.

64. Tauzin L, Joubert C, Noel A-C, Bouissou A, Moulies M-E. Effect of persistent patent ductus arteriosus on mortality and morbidity in very low-birthweight infants. Acta Paediatr. 2012;101:419-23. doi: 10.1111/j.1651-2227.2011.02550.x.

65. Ferreira $\mathrm{CH}$, Carmona F, Martinez FE. Prevalence, risk factors and outcomes associated with pulmonary hemorrhage in newborns. J Pediatr (Rio J). 2014;90:316-22. doi: 10.1016/j. jped.2013.12.008.

66. Zahr RA, Marron-Corwin M. Neonatal pulmonary hemorrhage. NeoReviews 2012;13:e302-6. doi: 10.1542/neo.13-5-e302.

67. Stucin Gantar I, Babnik J, Kornhauser Cerar L, Sinkovec J, Wraber B. Prenatal and postnatal risk factors for developing bronchopulmonary dysplasia. Signa Vitae. 2011;6:46-51.

68. Ohlsson A, Walia R, Shah SS. Ibuprofen for the treatment of patent ductus arteriosus in preterm and/or low birth weight infants. Cochrane Database Syst Rev. 2013;(4):CD003481. doi: 10.1002/14651858.CD003481.pub5.

69. Benitz WE. Patent ductus arteriosus: to treat or not to treat? Arch Dis Child Fetal Neonatal Ed. 2012;97:F80-2. doi: 10.1136/ archdischild-2011-300381.

70. Marshall DD, Kotelchuck M, Young TE, Bose CL, Kruyer L, O'Shea TM. Risk factors for chronic lung disease in the surfactant era: a North Carolina population-based study of very low birth weight infants. North Carolina Neonatologists Association. Pediatrics. 1999;104:1345-50.

71. Noerr B. Current controversies in the understanding of necrotizing enterocolitis Part 1. Adv Neonatal Care. 2003;3:107-20.

72. Shortland DB, Gibson NA, Levene MI, Archer LNJ, Evans DH, Shaw DE. Patent ductus arteriosus and cerebral circulation in preterm infants. Dev Med Child Neurol. 1990;32:386-93.

73. Ibrahim TK, Haium AAA, Chandran S, Rajadurai VS. Current Controversies in the Management of Patent Ductus Arteriosus in Preterm Infants. Indian Pediatr. 2014;51:289-94. 